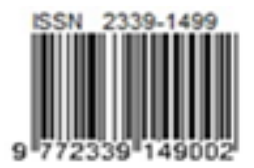

\title{
Pengembangan Produk Power Charger Portable dengan Menggunakan Metode Quality Function Deployment (QFD)
}

\author{
Rony Prabowo', Maulana Idris Zoelangga ${ }^{2}$ \\ 1,2 Fakultas Teknologi Industri, Jurusan Teknik Industri - Institut Adhi Tama Surabaya \\ email : rony.prabowo@itats.ac.id, Maoelanasm1@gmail.com
}

\begin{abstract}
Technological sophistication has become the necessity of human life, because it can facilitate the survival of human life. One of the technological sophistication that is needed by humans is the mobile phone. Mobile communication devices require electrical power sourced from the battery, when it runs out of power [1]requires a power source to restore power. Portable charger products [2]is one of the products that are always in need of mobile phone users. In this study, portable charger products have the advantage that can charge electric power just by moving it without using the electricity that comes from PLN. The purpose of this study is to determine the characteristics of portable charger products and designing products in accordance with the voice of customers obtained. In the first stage, the preparation and distribution of questionnaires to obtain voice of customer, create a technical response, create a house of quality, which then design the manufacture of portable charger products in accordance with customer wishes. Based on the research, the result of design of portable charger product with the length of $15 \mathrm{~cm}$, width $8 \mathrm{~cm}$, thickness $3 \mathrm{~cm}$ and has the adhesive as long as $25 \mathrm{~cm}$.
\end{abstract}

Keywords: technology, phone, portable, charger, function

Abstrak

Kecanggihan teknologi telah menjadi kebutuhan hidup manusia, karena dapat mempermudah kelangsungan hidup manusia. Salah satu kecanggihan teknologi yang sangat dibutuhkan oleh manusia adalah handphone. Alat komunikasi handphone membutuhkan daya listrik yang bersumber dari baterai dan memerlukan sumber listrik untuk memulihkan daya tersebut. Produk charger portable merupakan salah satu produk yang selalu di butuhkan para pengguna telepon genggam. Dalam penelitian ini, produk charger portable memiliki keunggulan yang dapat mengisi daya listrik hanya dengan konsep charger akan terisi pada sat pengguna bergerak atau digerakkan secara manual untuk menghasilkan energy kinertik tanpa menggunakan aliran listrik yang bersumber dari PLN. Tujuan dari penelitian ini adalah menentukan karakteristik produk charger portable dan merancang produk sesuai dengan voice of customer yang diperoleh. Pada tahap pertama dilakukan penyusunan dan penyebaran kuesioner untuk memperoleh voice of customer, membuat respon teknis, membuat house of quality, yang selanjutnya merancang pembuatan produk charger portable sesuai dengan keinginan customer. Berdasarkan penelitian tersebut, diperoleh hasil rancangan produk charger portable dengan ukuran panjang $15 \mathrm{~cm}$, lebar $8 \mathrm{~cm}$, ketebalan $3 \mathrm{~cm}$ dan memiliki perekat sepanjang $25 \mathrm{~cm}$.

Kata kunci: teknologi, handphone, charger, quality, function, deployment

\section{Pendahuluan}

Dengan kesibukan mobilitas yang tinggi sebagian besar masyarakat, membuat alat komunikasi misalnya handphone menjadi suatu hal yang sangat dibutuhkan. Alat komunikasi seperti handphone sudah menjadi bagian dari kebutuhan masyarakat pada umumnya, hal ini disebabkan handphone merupakan alat komunikasi yang cukup praktis dan efektif. Alat komunikasi handphone membutuhkan daya listrik yang bersumber dari baterai, apabila terjadi kehabisan daya memerlukan sumber listrik untuk memulihkan daya baterai agar dapat mengoperasikan handphone dengan optimal (Jaelani, 2012).
Kegiatan pengisian daya baterai ini dapat mengganggu aktifitas mobilitas manusia. Alat pengisian daya baterai yang ada saat ini masih belum dapat mengimbangi mobilitas manusia, maka diperlukan suatu pengembangan untuk menyesuaikan kebutuhan manusia saat ini.

Produk charger portable yang ada sekarang masih menggunakan penyimpanan daya yang mana masih memerlukan daya listrik untuk mengembalikan dayanya. Produk yang tidak bisa disebut dengan charger portable namun disebut sebagai power bank. Produk tersebut dapat digunakan untuk mengisi daya baterai handphone namun memiliki batasan karena juga menggunakan 
kapasitas. Dengan menggunakan gaya gesek yang dapat memberikan aliran listrik, penelitian ini ingin menciptakan suatu alat pengisi daya yang menggunakan gaya gesek. Gaya gesek yang ditimbulkan oleh magnet dan tembaga dapat menghasilkan suatu energi listrik, maka hal tersebut dapat digunakan sebagai sumber energi listrik daya rendah.

Produk charger portable merupakan salah satu produk yang selalu di butuhkan para pengguna telepon genggam. Dalam penelitian ini produk charger portable yang akan dikembangkan memiliki keunggulan yang berbeda dengan produk yang telah ada, yaitudapat mengisi daya listrik hanya dengan menggerakkannya tanpa menggunakan aliran listrik yang bersumber dari PLN. Selain itu produk ini juga dapat digunakan pada saat perjalanan jauh yang tidak terdapat sumber daya listrik dari PLN.

\section{Metode Penelitian}

\section{Perancangan dan Pengembangan Produk}

Perancangan adalah penggambaran, perencanaan dan pembuatan sketsa atau pengaturan dari beberapa elemen yang terpisah ke dalam satu kesatuan yang utuh dan berfungsi (Kuswidiyanto, 2013). Rancangan atau desain (design) adalah dimensi yang unik, dimensi ini banyak menawarkan aspek emosional dalam mempengaruhi kepuasan pelanggan. Rancangan adalah totalitas fitur yang mempengaruhi penampilan dan fungsi produk tertentu menurut yang diisyaratkan oleh pelanggan (Marimin, 2016). Desain baru dapat diartikan sebagai pengembangan produk yang pada intinya sama dengan produk yang telah dipasarkan oleh perusahaan tetapi lebih memiliki keunggulan. Pengembangan desain dapat ditujukan sebagai suatu proses berturutturut didasarkan pada informasi tertentu (Trisna, et.al, 2012). Tahap-tahap pengembangan ini dapat dilakukan melalui penyaringan analisa,

Desain produk, atau dalam bahasa keilmuan disebut juga Desain Produk Industri, adalah sebuah bidang keilmuan atau profesi yang menentukan bentuk dari sebuah produk manufaktur, mengolah bentuk tersebut agar sesuai dengan pemakainya dan sesuai dengan kemampuan proses produksinya pada industri. Sedang pengembangan produk merupakan serangkaian aktivitas yang dimulai dari perencanaan kemudian di akhiri dengan tahapan produksi yang mengacu pada penawaran pasar. Adapun parameter rancangan yang didefinisikan sebagai berikut (Urlich and Eppinger, 2013): (1) Gaya (style), menggambarkan penampilan dari suatu produk; (2) Daya Tahan (durability), menggambarkan umur beroperasinya produk dalam kondisi normal atau mengalami kerusakan; (3) Kehandalan (reliability), merupakan ukuran probabilitas bahwa produk tertentu tidak akan rusak atau gagal dalam periode waktu tertentu; (4) Mudah diperbaiki (repairability), ukuran kemudahan untuk memperbaiki produk ketika produk mengalami kerusakan.

Dalam dunia bisnis dan marketing, istilah pengembangan produk (product development) sudah lazim dibicarakan, dibahas dan dianalisis. Secara umum pengembangan produk dapat diartikan sebagai suatu usaha yang dilakukan perusahaan untuk menambah manfaat, desain dan layanan pada barang dan jasa. Mengingat setiap produk memiliki umur (life cycle) maka pengembangan produk perlu dilakukan secara terencana (Nugraha, 2015). Pengembangan produk juga memungkinkan perusahaan untuk menyediakan produk baru sebelum produk lama mengalami penurunan (decline). Pengembangan produk adalah rangkaian proses yang diawali dengan analisa persepsi dan peluang pasar, sebagai tahap akhirnya adalah produksi, penjualan dan pengiriman produk yang dianggap memiliki nilai lebih dibandingkan dengan produk terdahulu (Ulrich, 2010).

Beberapa dimensi yang digunakan sebagai parameter pengembangan produk yang sukses (Cohen, 2010): (a) menghasilkan keuntungan; (b) kualitas produk yang semakin baik, yang berarti juga harus meningkatkan kepuasan konsumen; (c) biaya produk lebih rendah, biaya produk berpengaruh terhadap laba yang dihasilkan; (d) waktu pengembangan produk yang cepat menunjukkan kemampuan perusahaan untuk berkompetisi; (e) biaya pengembangan, semakin rendah biaya pengembangan semakin baik. Pengembangan produk (product development) adalah suatu kegiatan atau aktifitas yang dilakukan dalam menghadapi kemungkinan perubahan suatu produk ke arah yang lebih baik sehingga dapat memberikan daya guna maupun daya pemuas yang lebih besar (Dweyer, 2013). Pengembangan produk (product development) adalah suatu istilah yang terbalas meliputi kegiata teknis seperti riset produk, rekayasa produk dan desain (Imron, 2014).

\section{Quality Function Deployment (QFD)}

Identifikasi kebutuhan pelanggan sangat berguna dalam proses pengembangan produk untuk semakin mendekatkan pada sasaran bagaimanakah sebenarnya atribut atau produk yang diinginkan oleh konsumen (Prabowo dan Purwanto, 2016). Model identifikasi kebutuhan pelanggan dapat ditentukan menggunakan konsep Quality Function Develoyment (QFD). Konsep QFD 
pertama kali dikemukaan oleh Dr.Yoji Akao di Jepang pada 1966. Akao mendefinisikan QFD sebagai sebuah metode untuk desain kualitas dengan ekspektasi konsumen, kemudian menerjemahkannya ke disain target dan point kritial kualitas, sehingga dapat digunakan pada pengembangan produksi/jasa. QFD adalah sebuah tool manajemen yang sangat efektif, berdasarkan ekspektasi konsumen yang umum digunakan untuk mengendalikan proses pengembangan produk atau mengembangkan jasa dalam sebuah industri.

QFD yang berasal dari bahasa Jepang yaitu Hin Shitsu Kino Ten Kai. Dalam bahasa jepang Hin Shitsu berarti kualitas, atribut atau feature, Kino berarti fungsi atau mekanisasi sedangkan Ten Kai berarti penyebar luasan pengembangan atau evolusi (Cohen, 2012). QFD pertama kali dikembangkan pada perusahaan Mitsubishi's Kobe Shipyard, dan selanjutnya diadopsi oleh Toyota. Dalam perkembangannya, Ford Motor Company dan Xerox menyebarluaskan konsep ini di Amerika. Sehingga metode ini mulai populer dan banyak diterapkan pada perusahaan besar di Jepang, Amerika dan Eropa. QFD merupakan metode untuk perancangan produk dengan menterjemahkan kebutuhan pelanggan, serta menemukan tanggapan inovatif terhadap kebutuhan tersebut dengan memperbaiki proses hingga tercapainya produk atau jasa dengan atribut yang memperioritaskan keinginan pelanggan (Mutiara, et.al, 2013). Penerapan QFD sebagai upaya mengindentifikasi keinginan dan kebutuhan pelanggan menggunakan format matriks yang disusun dalam suatu bentuk yang sering disebut dengan nama House of Quality ( $\mathrm{HoQ})$.

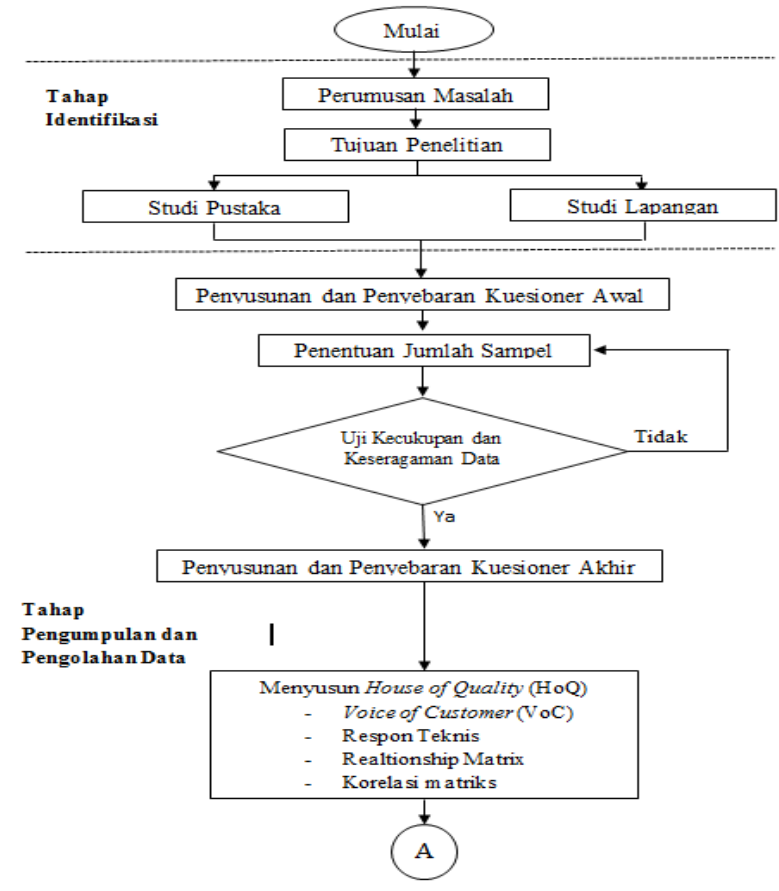

Tujuan dari Quality Function Deployment (QFD) sendiri tidak hanya memenuhi sebanyak mungkin harapanharapan pelanggan, juga berusaha melampaui harapan-harapan pelanggan sebagai cara untuk berkompetensi dengan saingannya, sehingga diharapkan pelanggan tidak menolak dan tidak komplain, tapi malah menginginkannya (Prabowo, 2011). Team Quality Function Deployment harus membuat produk atau jasa lebih menarik daripada produk/jasa yang sudah ada atau lebih menarik dibandingkan produk/jasa pesaing-pesaingnya (Batan, 2012). Quality Function Deployment (QFD) digunakan untuk memastikan bahwa perusahaan memusatkan perhatiannya terhadap kebutuhan pelanggan sebelum setiap pekerjaan perancangan dilakukan. Ini mungkin memperpanjang tahap perencanaan desain proyek, akan tetapi secara umum mengurangi baik jumlah waktu secara keseluruhan yang diperlukan untuk tahap perancangan maupun jumlah perubahan rancangan setelah diluncurkan (Bayu, 2014).

Penggunaan metodologi QFD dalam proses perancangan dan pengembangan produk merupakan suatu nilai tambah bagi perusahaan. Sebab perusahaan akan mempunyai keunggulan kompetitif dengan menciptakan suatu produk atau jasa yang mampu memuaskan konsumen. Manfaatmanfaat yang diperoleh oleh penerapan QFD dalam proses perancangan produk adalah (Dale, 2012): (1) meningkatkan kehandalan produk; (2) meningkatkan kualitas produk; (3) meningkatkan kepuasan konsumen; (4) memperpendek time to market; (5) mereduksi biaya perancangan; (6) meningkatkan komunikasi; (7) meningkatkan produktivitas.

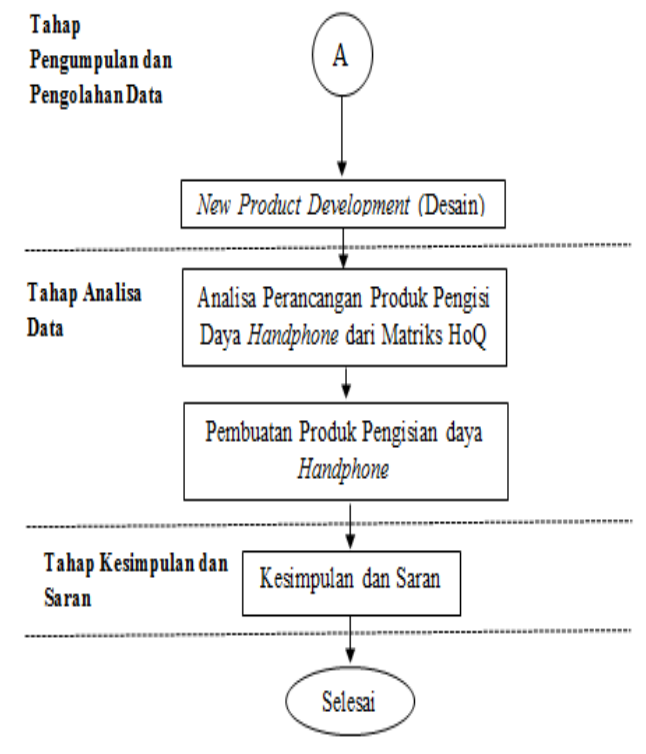

Gambar 1. Metodologi Penelitian 
Tahapan dalam metodologi penelitian ini terdapat beberapa tahapan yang akan dijelasan sebagai berikut :

1. Teknik Pengumpulan Data

Adapun cara atau teknik yang digunakan dalam pengumpulan dan pengolahan data dalam penelitian ini adalah dengan menggunakan Kuesioner yang melalui beberapa tahapan diantaranya :

a. Penyusunan dan Penyebaran Kuesioner Tahap Awal

Pada tahap ini kuesioner terbuka bertujuan untuk mengidentifikasi halhal yang diinginkan konsumen (The voice of customer) pengisi daya handphone dengan menjadikan jawaban-jawaban responden yang sama dan menjadi tujuan, dari tujuan jawaban ini akan diketahui spesifikasi produk pengisi daya handphone yang paling banyak diinginkan oleh konsumen. Yang menjadi responden keinginan konsumen ini adalah masyarakat kota Surabaya dengan rentan usia 20 hingga 40 tahun atau pengguna pengisi daya handphone.

b. Penentuan jumlah sampel yang didapat dari Kuesioner tahap awal.

c. Pengujian keseragaman dan kecukupan data

Tabel 1 merupakan atribut-atribut awal yang didapatkan dari Kuesioner terbuka.

Tabel 1. Data Atribut Produk Charger Portable

\begin{tabular}{|c|l|}
\hline No. & \multicolumn{1}{|c|}{ Atribut } \\
\hline 1. & Mudah digunakan \\
\hline 2. & Tidak mudah rusak \\
\hline 3. & Daya tahan lama \\
\hline 4. & Tidak memakan banyak tempat \\
\hline 5. & Harga terjangkau \\
\hline 6. & Ringan \\
\hline 7. & Desain menarik \\
\hline 8. & Mudah dipegang \\
\hline 9. & Memiliki banyak port usb \\
\hline 10. & Mudah dibawa kemana-mana \\
\hline 11. & Sebagai penerangan \\
\hline
\end{tabular}

2. Penyusunan dan Penyebaran Kuesioner Akhir
Data diatas merupakan hasil dari penyebaran Kuesioner awal dimana data tersebut didapatkan dari konsumen pengguna charger portable yang kemudian di kategorikan sebagai bahasa pengembangan produk Kuesioner akhir disusun dari hasil pengajuan dan kesimpulan Kuesioner pertama untuk memperoleh data kuantitatif yang berupa data tentang kepentingan (bobot), tingkat kepuasan yang diharapkan para responden (pengguna charger portable). Kuesioner tahap akhir ini disebarkan kepada 50 orang responden dan dari hasil penyebaran Kuesioner tahap akhir ini dapat dilakukan pengolahan data lebih lanjut.

\section{Penentuan Jumlah Sampel}

Suatu pengukuran dibutuhkan sampel atribut, dalam hal ini populasi pengguna charger portable yang mayoritas para pendaki gunung di wilayah kota Surabaya yang selama ini membutuhkan pengisi daya untuk bepergian. Dalam menentukan jumlah sampel atribut penelitian, maka digunakan perhitungan dengan metode Bernoulli ukuran sampel minimum untuk menguji kecukupan data dari Kuesioner. Didapat dari perhitungan Bernoulli dengan rumus sebagai berikut (Feri dan Juju, 2010) :

$$
N=\frac{\left(Z_{\propto / 2}\right)^{2} \cdot p \cdot q}{e^{2}}
$$

Dimana:

$N=$ Jumlah sampel minimum

$Z=$ Nilai distribusi normal

$a=$ Tingkat signifikasi

$p=$ Proporsi jumlah Kuesioner yang dijawab benar

$q=1-p$, proporsi jumlah Kuesioner yang dijawab salah

$e=$ Toleransi eror

$$
\begin{gathered}
N=\frac{\left(Z_{0.05 / 2}\right)^{2} \cdot\left(\frac{49}{50}\right) \cdot\left(\frac{1}{50}\right)}{0.05^{2}} \\
=\frac{(1.96)^{2} \cdot\left(\frac{49}{50}\right) \cdot\left(\frac{1}{50}\right)}{0.05^{2}} \\
=\frac{(3.84) \cdot(0.98) \cdot(0.02)}{0.0025} \\
=30,11 \sim 31 \text { responden }
\end{gathered}
$$

4. Analisa Matriks House of Quality (HoQ) 
Hasil akhir dari metode QFD merupakan sebuah rencana pengembangan produk. Rencana pengembangan dapat terlihat pada nilai target yang terletak di bagian bawah House of Quality (HoQ). Metode QFD mencakup proses-proses yang lengkap mulai dari identifikasi permasalahan sampai tercapainya sasaran proyek pengembangan melallui lahirnya spesifikasi desain baru yang sesuai dengan keinginan konsumen. Dalam QFD terdapat nilai tingkat kepentingan yang dimana tingkat nilai kepentingan tersebut menunjukkan bahwa semakin tinggi nilainya, maka atribut semakin tinggi nilai eksistensinya, untuk tingkat kebutuhan ditunjukkan oleh nilai raw weight yang dimana mempresentasikan tinggi atau rendahnya nilai suatu atribut, dimana nilai raw weight ini akan dijadikan dasar dalam menentukan prioritas utama perbaikan terhadap rancangan produk charger portable yang dimana dengan keinginan konsumen. Prioritas tingkat keinginan konsumen dapat dilihat pada tabel 2 berikut.

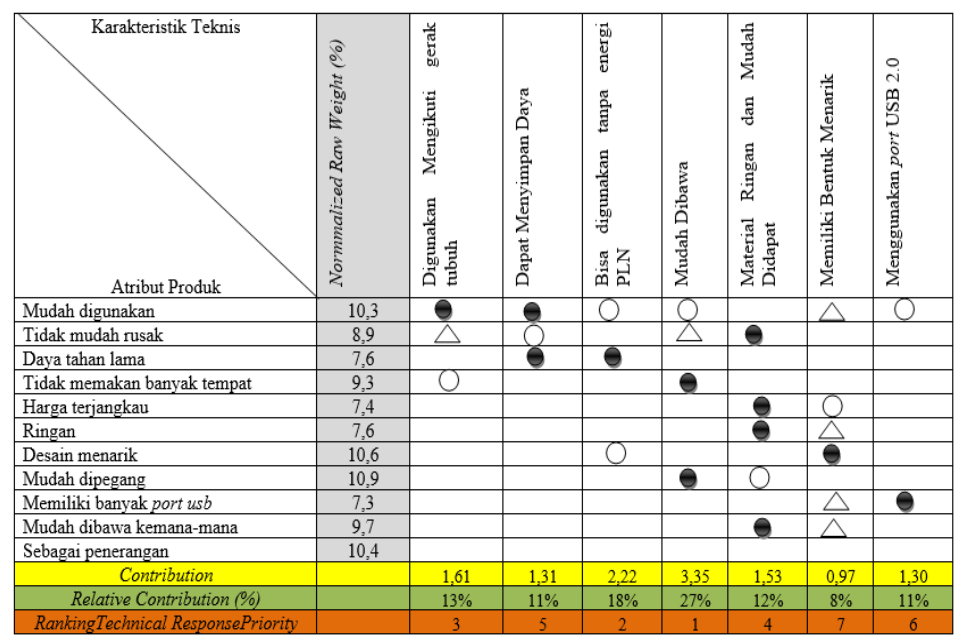

Gambar 2. Technical Matrix Product Charger Portable

Tabel 2 Prioritas Tingkat Keinginan Konsumen

\begin{tabular}{|l|c|c|}
\hline \multicolumn{1}{|c|}{ Atribut } & $\begin{array}{c}\text { Raw } \\
\text { Weight }\end{array}$ & $\begin{array}{c}\text { Normalized } \\
\text { Raw } \\
\text { Weight (\%) }\end{array}$ \\
\hline Mudah digunakan & 4,78 & 10,3 \\
\hline Tidak mudah rusak & 4,17 & 8,9 \\
\hline Daya tahan lama & 3.28 & 7,6 \\
\hline $\begin{array}{l}\text { Tidak memakan banyak } \\
\text { tempat }\end{array}$ & 4,32 & 9,3 \\
\hline Harga terjangkau & 3,44 & 7,4 \\
\hline Ringan & 3,55 & 7,6 \\
\hline Desain menarik & 4,94 & 10,6 \\
\hline Mudah dipegang & 5,10 & 10,9 \\
\hline Memiliki banyak port USB & 3,41 & 7,3 \\
\hline Mudah dibawa kemanapun & 4,53 & 9,7 \\
\hline Sebagai penerangan & 4,86 & 10,4 \\
\hline
\end{tabular}

Tabel 3 Perangkingan Karakteristik Teknis

\begin{tabular}{|l|c|c|c|}
\hline $\begin{array}{l}\text { Karakteristik } \\
\text { Teknis }\end{array}$ & Contributions & $\begin{array}{c}\text { Relative } \\
\text { Contributions } \\
\text { (\%) }\end{array}$ & Ranking \\
\hline $\begin{array}{l}\text { Material } \\
\text { Ringan dan } \\
\text { Mudah } \\
\text { Didapat }\end{array}$ & 3,35 & 27 & 1 \\
\hline $\begin{array}{l}\text { Mudah } \\
\text { Dibawa }\end{array}$ & 2,22 & 18 & 2 \\
\hline $\begin{array}{l}\text { Dapat } \\
\text { Menyimpan } \\
\text { Daya }\end{array}$ & 1,61 & 13 & 3 \\
\hline $\begin{array}{l}\text { Tidak } \\
\text { Mudah } \\
\text { Rusak }\end{array}$ & 1,53 & 12 & 4 \\
\hline $\begin{array}{l}\text { Digunakan } \\
\text { Mengikuti } \\
\text { Gerak } \\
\text { Tubuh }\end{array}$ & 1,31 & 11 & 5 \\
\hline $\begin{array}{l}\text { Bisa } \\
\text { digunakan } \\
\text { tanpa } \\
\text { energi PLN }\end{array}$ & 1,30 & 11 & 6 \\
\hline
\end{tabular}

Analisa yang dilakukan pada karakteristik teknis ini merupakan analisa kontribusi prioritas terhadap seetiap karakteristik teknis. Kontribusi prioritas akan menunjukkan seberapa besar suatu karakteristik teknis mempunyai pengaruh terhadap kulitas produk. Semakin besar nilai kontribusinya, maka semakin perlu diprioritaskan.

\section{Perancangan Produk Charger Portable}

Produk charger portable merupakan suatu alat yang dapat digunakan untuk menjaga daya telepon genggam yang selama ini menggantungkan energi listrik PLN untuk menjaga daya. Dengan hadirnya produk ini dapat mempermudah para pendaki untuk tetap mempertahankan daya telepon genggam yang dibawa pada saat bepergian. Berikut adalah desain produk charger portable.

\section{Gambar 2. Disain Produk Charger Portable}

Desain dari produk charger portable merupakan hasil dari penerapan suara pelanggan yang didapatkan dari Kuesioner. Dari beberapa atribut yang didapat kemudian diterapkan dengan beberapa respon teknis, sehingga dapat memberikan desain terbaru dari produk charger portable. Dengan menerapkan metode perubahan energi gerak menjadi energi 
listrik produk ini mampu memberikan daya yang mampu bertahan lebih lama. Selain itu produk charger portable dapat dioperasikan tanpa harus digerakkan menggunakan tangan namun mampu digerakkan hanya dengan mengikuti gerakan tubuh.

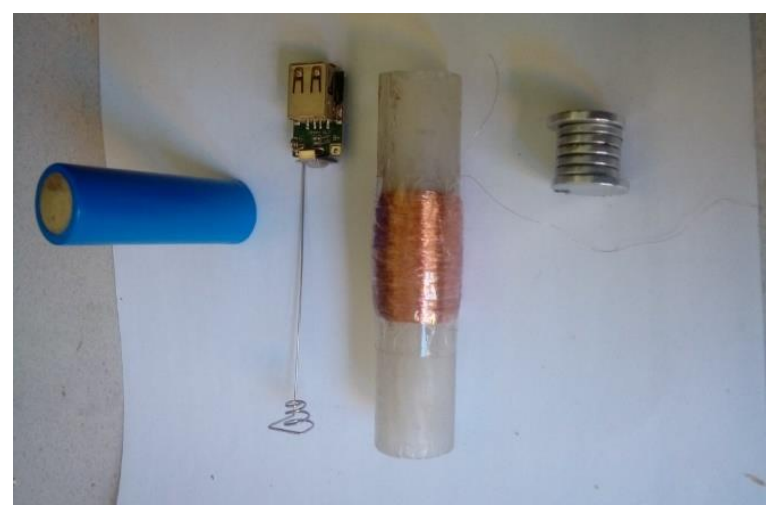

Gambar 3. Komponen Produk Charger Portable

\section{Tahap Evaluasi Rancangan}

Sebelum dipasarkan produk maka untuk menjamin bahwa produk akan berhasil digunakan dan bisa diterima pasar adalah sebagai berikut:

a. Produk akan dibuat dalam jumlah kecil antara 10 -25 untuk diberikan kepada konsumen dan konsumen memberikan testimoni terutama masukan mengenai kekurangan atau fitur apa yang perlu diperbaiki

b. Merekrut sebanyak tim ahli yang kompeten sebanyak 3 orang untuk verifikasi alat dan memberikan saran agar produk lebih baik

\section{Kesimpulan}

Atribut tingkat kebutuhan konsumen atau voice of customer terhadap pengembangan charger portable menghasilkan nilai Normalize Raw Weight 10,9 adalah produk mudah dipegang oleh pengguna, dengan Normalize Raw Weight 10,6 adalah desain produk yang menarik sesuai dengan keiginan pengguna, dengan Normalize Raw Weight 10,3 adalah produk mudah digunakan oleh pengguna, dengan Normalize Raw Weight 9,7 adalah mudah dibawa kemena-mana olehpengguna.

Dari gambaran target karakteristik teknik produk charger portable yang di dapatkan dari hasil analisa menggunakan Quality Function Deployment (QFD) adalah produk charger portable mudah dibawa kemana-mana dengan nilai kontribusi sebesar $27 \%$, produk charger portable bisa menggunakan energi listrik dari pln maupun tidak dengan nilai kontribusi sebesar $18 \%$, produk charger portable dapat digunakan megikuti gerak tubuh dengan nilai kontribusi sebesar $13 \%$, produk charger portable menggunakan material yang ringan dan mudah didapatkan dengan nilai kontribusi sebesar $12 \%$, produk charger portable dapat menyimpan daya listrik dengan nilai kontribusi sebesar $11 \%$.

Hasil rancangan produk charger protable dengan ukuran panjang $15 \mathrm{~cm}$, lebar $8 \mathrm{~cm}$, ketebalan $3 \mathrm{~cm}$ dan memiliki perekat sepanjang $25 \mathrm{~cm}$. Dalam pengembangan produk charger portable dengan melihat hasil dari analisa Quality Function Deployment (QFD) produk charger portable mudah dibawa kemana-mana, bisa digunakan tanpa energi PLN, dapat digunakan mengikuti gerak tubuh pengguna, menggunakan material yang ringan dan mudah didapatkan, dan dapat menyimpan daya listrik.

\section{Daftar Pustaka}

Batan, I. M. (2012). Desain Produk. Edisi Pertama. Guna Widya. Surabaya

Bayu, C. (2014). Disain Pengembangan Produk Kursi Kelas dengan Metode QFD dan Kano. Jurnal Teknik Industri Volume 4 Isu 2, hal 44 - 61. Universitas Kristen Petra. Surabaya

Cohen, L. (2010). Quality Function Deployment How to Make QFD Work for You. Massachussets : AddisonWesley

Dale, S. (2012). Learning Theories An Educational Perspective. Pearson Education, Upper Sadle River. New Jersey

Feri, S dan Juju, D. (2010). Data Mining Meramalkan Bisnis Perusahaan, Elex Media Komputindo. Jakarta

Imron, J. (2014). Rancangan Produk Charger Handphone Portable Dengan Metode Quality Function Deployment (QFD). Jurnal Online Institut Teknologi Nasional Bandung. Vol.02 No.02 April 2014. ISSN: 2338-5081

Jaelani, E. (2012). Perencanaan Dan Pengembangan Produk Dengan Quality Function Deployment (QFD). Jurnal Sains \& Manajemen Akuntansi Vol.4 No.1/Mei/2012

Kuswidiyanto, T. (2013). Perancangan Produk Mesin Tetas Telur Tepat Guna Sebagai Upaya Peningkatan Produktivitas Ternak Unggas Dengan Metode Quality Function Deployment. Universitas Dian Nuswantoro. Semarang

Marimin, M. (2016). Aplikasi Teknik Pengambilan Keputusan Dalam 
Manajemen Rantai Pasok. Bogor: IPB Press

Mutiara, A., Arie, D dan Yuniar. (2013). Rancangan Meja Dapur Multifungsi Menggunakan Quality Function Deployment (QFD). Jurnal Online Institut Teknologi Nasional Bandung. Vol.1 No.2 Oktober 2013. ISSN: 2338-5081

Nugraha, H. (2015). Perancangan dan Pembuatan Charger Handphone Portable Menggunakan Sistem Penggerak Generator AC dengan Penyearah. Jurnal Akademi Teknik Telekomunikasi Purwokerto. Purwokerto

Prabowo, R dan Purwanto, B. (2016). New Product Development for Dryer Fish for SMEs Scale with Quality Function Deployment (QFD) Method. Prosiding
Seminar Internasional ICOEN 3, ISBN: 2356-3206, Hal. 327-336. Universitas Ciputra. Surabaya

Prabowo, R. (2011). Strategi Peningkatan Kualitas Dengan Metode QFD di PT. Karya Teknik Persada Surabaya. Jurnal Institut Teknologi Adhi Tama Surabaya

Trisna, Y., Ma'arif, S dan Akerman, K. (2012). Strategi Pengembangan Produk Susu Kedelai Dengan Penentuan Karakteristik Produk. Jurnal Teknik Industri ISSN :1411-6340 157

Ulrich, K. T and Eppinger, S.D. (2010). Perancangan dan Pengembangan Produk. Salemba Teknika. Jakarta 
Halaman ini sengaja dikosongkan

This page is intentionally left blank 